\title{
Regulation of the Expression of Tissue Inhibitor of Metalloproteinases and Collagenase by Retinoids and Glucocorticoids in Human Fibroblasts
}

\author{
Sheryl D. Clark, Dale K. Kobayashi, and Howard G. Welgus \\ Division of Dermatology, Department of Medicine, Jewish Hospital at Washington University Medical Center, St. Louis, Missouri 63110
}

\begin{abstract}
The regulation of the expression of interstitial collagenase and tissue inhibitor of metalloproteinases (TIMP) was examined in response to both retinoid compounds and glucocorticoids. Effective retinoids induced a dose-dependent, specific increase in the production of TIMP of $\sim$ two- to threefold by monolayer cultures of human fibroblasts derived from various tissues, while simultaneously causing a decrease in collagenase secretion of similar magnitude. These effects were apparent by 8-12 $h$ in culture and disappeared within $24 \mathrm{~h}$ after the withdrawal of retinoid compounds. The retinoid effect on TIMP production was mediated via an increased biosynthesis of new inhibitor protein. Similarly, increased steady state levels of TIMP messenger RNA (mRNA) accompanied by decreased quantities of collagenase mRNA were demonstrated, suggesting transcriptional control of the retinoid action. The data suggest that retinoids co-regulate the expression of collagenase and TIMP, and do so in an inverse manner.

Dexamethasone caused a dose-dependent, specific decrease in collagenase production without altering the biosynthesis of TIMP. These findings were paralleled by a marked reduction in collagenase mRNA, without any accompanying change in TIMP mRNA. Therefore, TIMP and collagenase expression appear to be independently modulated by glucocorticoids.
\end{abstract}

\section{Introduction}

The degradation of interstitial collagens is dependent upon the activity of collagenase, the enzyme that catalyzes the initial cleavage of the native collagen molecule (1). Control over collagenase activity in vivo is likely to be a complex biologic process involving factors such as the regulation of procollagenase biosynthesis, enzyme secretion from the cell, zymogen activation, and inhibition of active collagenase by proteinase inhibitors. Human skin fibroblasts in monolayer culture produce a collagenase inhibitor (tissue inhibitor of metalloproteinases [TIMP] $)^{1}$ that has been extensively studied and characterized $(2,3)$, and that may serve to regulate collagenase activity in the extracellular space.

\section{Address correspondence to Dr. Clark, Division of Dermatology, Jew- ish Hospital at Washington University Medical Center, 216 S. Kings- highway, St. Louis, MO 63110. \\ Received for publication 29 December 1986 and in revised form 14 May 1987.}

1. Abbreviation used in this paper: TIMP, tissue inhibitor of metalloproteinases.

J. Clin. Invest.

(C) The American Society for Clinical Investigation, Inc.

$0021-9738 / 87 / 11 / 1280 / 09 \$ 2.00$

Volume 80, November 1987, 1280-1288
Human fibroblast TIMP is a $28,500-\mathrm{D}$ glycoprotein (2) that inhibits a variety of metalloproteinases of connective tissue origin, including collagenase, gelatinase, and proteoglycanase (4). The purification of human skin fibroblast TIMP to homogeneity and subsequent development of specific antibody (2) led to the identification of this protein as a secretory product of human fibroblasts of diverse tissue origin, smooth muscle cells, osteoblasts (3), and human mononuclear phagocytes, including alveolar macrophages (5). Human skin fibroblast TIMP was also identified in several body fluids, including plasma, serum, and amniotic fluid (2), and as a constituent of the $\alpha$-granule of human platelets (6). The primary structure of human TIMP has recently been determined both by the isolation of the corresponding complementary DNA (cDNA) clone and nucleotide sequencing $(7,8)$, as well as by primary amino acid sequence analysis (8). This inhibitor molecule is capable of inhibiting active collagenase on a 1:1 molar stoichiometric basis (9) via the formation of a very high affinity (inhibition constant $\left.<10^{-9} \mathrm{M}\right)$, though noncovalent, enzyme-inhibitor complex $(10,11)$. The ubiquity of human TIMP and its ability to regulate the activity of several degradative enzymes suggests a major role for this molecule in modulating the turnover of human connective tissues.

A number of physiologic and pharmacologic agents have been identified that can regulate the production of collagenase by fibroblasts (12-19), but only phorbol esters and interleukin 1 (IL-1) have also been studied extensively with regard to their action on TIMP biosynthesis. Phorbol esters have been demonstrated to induce a dose-dependent increase in the production of both collagenase and TIMP by human fibroblasts (20, 21). Similarly, IL-1 has been shown to stimulate the synthesis of collagenase $(13,16,18,20)$ and of TIMP $(20)$ by a variety of human fibroblasts and synovial cells. These results have suggested to some investigators that collagenase and TIMP expression are generally regulated in the same direction, perhaps even in a coordinate manner.

Since both the retinoid compounds $(14,22,23)$ and glucocorticoids $(12,24,25)$ have been shown to specifically diminish collagenase production in fibroblasts, we examined the effect of such agent upon the expression of TIMP. Our data indicate that effective retinoids induce a dose-dependent, specific increase in TIMP synthesis that is generally two- to threefold above basal secretory rates, while simultaneously reducing collagenase secretion by a similar magnitude. The retinoid effect on TIMP and collagenase production is apparent by 8-12 $h$ in culture, and disappears within $24 \mathrm{~h}$ after removal of the agent. The enhanced production of TIMP is mediated by an increase in the biosynthesis of new inhibitor protein as shown by metabolic labeling and immunoprecipitation, and is accompanied by increased steady state levels of TIMP messenger RNA (mRNA). Since the efficacy of different retinoid compounds, dose response, time course, and modulation of mRNA levels are very similar for both TIMP and collagenase, retinoids appear to co-regulate the expression of these fibro- 
blast proteins, albeit in an inverse manner. In addition to the retinoid compounds, we have also studied regulation by glucocorticoids such as dexamethasone. These steroids promote a dose-dependent, specific decrease in collagenase production that is not accompanied by any change in the synthesis of TIMP. Therefore, collagenase and TIMP expression appear to be independently regulated by glucocorticoids. These data indicate that multiple mechanisms exist for controlling the expression of TIMP and collagenase by human fibroblasts.

\section{Methods}

\section{Reagents}

All-trans-retinoic acid, retinal, retinol, and dexamethasone were obtained from Sigma Chemical Co. (St. Louis, MO). Etretinate (R0109359), etretin (R010-1670), and 13-cis-retinoic acid (R04-3780) were kindly provided by Dr. Peter Sorter of Hoffmann-La Roche, Inc. (Nutley, $\mathrm{NJ}$ ). All retinoids were stored at $-80^{\circ} \mathrm{C}$, protected from light, and were used within 8 wk of receipt. $\left[{ }^{3} \mathrm{H}\right]$ leucine (NET-460, 146.5 $\mathrm{Ci} / \mathrm{mmol}$ ) was obtained from New England Nuclear (Boston, MA) and stored at $4^{\circ} \mathrm{C}$.

\section{Culture methods}

Cells. Monolayer cultures of normal adult human skin fibroblasts were inititated from cells obtained from the American Type Culture Collection, Rockville, MD (CRL 1454 and 1471) and the Human Genetic Mutant Cell Repository, Camden, NJ (GM 3651 and 4390), or by explant culture techniques (JoHa) (26). Human gingival fibroblasts were obtained from the American Type Culture Collection (CRL 1292). Adult human lung fibroblasts were kindly provided by J. Clark, University of Washington, Seattle (BaHa). Human fetal lung fibroblasts were purchased from the Human Genetic Mutant Cell Repository (AG 4393). Human fetal skin fibroblasts were obtained from explant culture by techniques described previously (EGA 5209) (26), and from the Human Genetic Mutant Cell Repository (AG 4449).

Retinoids and dexamethasone. Both the retinoid compounds and dexamethasone were prepared from powder as $10^{-2} \mathrm{M}$ solutions. The retinoids were dissolved in $\mathrm{Me}_{2} \mathrm{SO}$ and the steroid in absolute ethanol. Each agent was then added to culture medium and diluted accordingly. Control cultures contained an appropriate concentration of either $\mathrm{Me}_{2} \mathrm{SO}$ or ethanol. Any excess retinoid or dexamethasone was discarded after each experiment.

C'll culture. Fibroblasts were subcultured as monolayers in Dulbecco's modified Eagle's medium: high glucose plus glutamine (DMEM; Sigma Chemical Co.) containing 10\% fetal calf serum, 200 $\mathrm{U} / \mathrm{ml}$ penicillin, $200 \mu \mathrm{g} / \mathrm{ml}$ streptomycin, and $30 \mathrm{mM}$ Hepes buffer (pH 7.6). Cultures were maintained in humidified air with $5 \% \mathrm{CO}_{2}$ at $37^{\circ} \mathrm{C}$.

For all experiments, identical secondary cultures of fibroblasts were initiated from a single pool of cells and grown to visual confluence $\left(\sim 4 \times 10^{5}-9 \times 10^{5}\right.$ cells/35-mm-diameter cluster well; $1 \times 10^{6}-2$ $\times 10^{6}$ cells $/ 25-\mathrm{cm}^{2}$ flask; $4 \times 10^{5}-5 \times 10^{6}$ cells $/ 75-\mathrm{cm}^{2}$ flask). Serumcontaining medium was then removed and the cells were washed several times with Hanks' balanced salt solution (HBSS; KC Biological Inc., Lenexa, KS). Culture medium containing $10 \%$ fetal calf serum or $0.4 \%$ bovine serum albumin (BSA), and retinoid, dissolved in $\mathrm{Me}_{2} \mathrm{SO}$, or dexamethasone, in absolute ethanol, was then added to the cell layer. Control cultures contained Dulbecco's modified Eagle's medium with either serum or $0.4 \%$ BSA, plus an appropriate concentration of $\mathrm{Me}_{2} \mathrm{SO}$ or absolute ethanol. All experiments were performed using two to four replicates for each tested condition.

Dose response. To assess the effect of all-trans-retinoic acid and of dexamethasone upon the production of collagenase and TIMP by human skin fibroblasts, replicate secondary cultures were grown to confluence in 35-mm-diameter cluster wells. The cell layers were then exposed to concentrations of all-trans-retinoic acid ranging from $10^{-12}$ to $10^{-5} \mathrm{M}$ or dexamethasone, from $10^{-11}$ to $10^{-7} \mathrm{M}$ for $48 \mathrm{~h}$. The conditioned media were collected and assayed by enzyme-linked immunosorbent assay (ELISA) for collagenase (27) and TIMP (3). Similar methodology was employed to examine the effect of all-trans-retinoic acid upon collagenase and TIMP production by fibroblasts of various tissue origin; however, these cells were exposed to $10^{-5}$ and $10^{-6} \mathrm{M}$ concentrations of the retinoid compound.

Time course. The time course characterizing the effect of all-transretinoic acid on collagenase and TIMP production was examined by incubating confluent cultures of human skin fibroblasts in $75-\mathrm{cm}^{2}$ flasks with $20 \mathrm{ml}$ of serum-containing medium which included $10^{-5} \mathrm{M}$ all-trans-retinoic acid or the appropriate concentration of $\mathrm{Me}_{2} \mathrm{SO}$, and then removing $400 \mu \mathrm{l}$ aliquots from each flask after $2,4,8,10,12,24$, 36 , and $48 \mathrm{~h}$ of incubation. To study the release of cells from retinoid effects, replicate $75-\mathrm{cm}^{2}$ flasks were exposed to $10^{-5} \mathrm{M}$ all-trans-retinoic acid or $\mathrm{Me}_{2} \mathrm{SO}$ alone for $48 \mathrm{~h}$. The cultures were then washed several times with HBSS, after which $20 \mathrm{ml}$ of fresh serum-containing medium without retinoid was added to the flasks. Samples of conditioned media $(400 \mu \mathrm{l})$ were removed at $4,8,24,36$, and $56 \mathrm{~h}$ for analysis of immunoreactive collagenase by ELISA. Since TIMP production in culture tended to plateau after $48 \mathrm{~h}$, probably due to the depletion of essential nutrients from culture medium, the release of TIMP expression from the effects of retinoid were examined using a slightly different experimental design. After exposure to retinoid for $\mathbf{4 8}$ $\mathrm{h}$, culture medium was changed to retinoid-free conditions and aliquots were collected after 8,24 , and $30 \mathrm{~h}$; at $48 \mathrm{~h}$, the medium was replaced again and samples were removed after an additional 6,12 , and $24 \mathrm{~h}$ for analysis of immunoreactive inhibitor protein.

Effect of different retinoids. To study the ability of different retinoid compounds to modulate the production of TIMP, replicate secondary cultures of human skin fibroblasts were exposed to $10^{-5}$ and $10^{-6} \mathrm{M}$ concentrations of all-trans-retinoic acid, retinal, retinol, 13-cis-retinoic acid, etretin, and etretinate in serum-containing medium for $48 \mathrm{~h}$. Samples of conditioned media were then analyzed for immunoreactive TIMP by ELISA.

\section{Assay procedures}

Collagenase and TIMP levels in conditioned media were quantitated immunologically by ELISA, each assay having a sensitivity of $\sim 5 \mathrm{ng}$ $(3,27)$. Each ELISA measures the total amount of that particular protein, whether it is present in a free or bound state. Furthermore, the same samples of conditioned media were generally assayed for both collagenase and TIMP.

To examine any possible effects upon total new protein synthesis by all-trans-retinoic acid or dexamethasone, replicate cultures of human skin fibroblasts were initiated in $35-\mathrm{mm}$-diameter cluster wells. After exposure to either retinoid, steroid, or the appropriate solvent control, the cells were washed three times with HBSS and then incubated for $8 \mathrm{~h}$ in otherwise identical culture medium containing 10 $\mu \mathrm{Ci} / \mathrm{ml}$ of $\left[{ }^{3} \mathrm{H}\right]$ leucine. The conditioned media were collected, after which the cell layer was scraped with a rubber policeman into a $1-\mathrm{ml}$ volume of buffer (phosphate-buffered saline, $\mathrm{pH} 7.5$ ), and then subjected to sonication. New protein synthesis was determined as the amount of $\left[{ }^{3} \mathrm{H}\right]$ leucine incorporated into trichloroacetic acid-insoluble material in the medium and cells. Conditioned media were simultaneously assayed for collagenase and TIMP by ELISA.

DNA content was determined by lysing the cell layer with $0.3 \mathrm{M}$ $\mathrm{NaOH}$ and assaying for DNA by established methods (28).

Metabolic labeling and immunoprecipitation of TIMP. Metabolic labeling studies designed to immunoprecipitate newly synthesized TIMP were conducted by exposing replicate cultures of fibroblasts in 35-mm-diameter cluster wells to serum-containing medium with and without $10^{-5}$ and $10^{-6} \mathrm{M}$ all-trans-retinoic acid for $24 \mathrm{~h}$. After extensive washing of the cell layer, the cultures were incubated for an additional $24 \mathrm{~h}$ in leucine-free, serum-free medium containing $10^{-5}$ and $10^{-6} \mathrm{M}$ all-trans-retinoic acid or an appropriate concentration of $\mathrm{Me}_{2} \mathrm{SO}$, and $30 \mu \mathrm{Ci} / \mathrm{ml}$ of $\left[{ }^{3} \mathrm{H}\right]$ leucine. Aliquots of $400 \mu \mathrm{l}$ of pulsed medium were then immunoprecipitated using TIMP-specific antibody 
$(2,3)$ and subjected to sodium dodecyl sulfate (SDS)-gel electrophoresis (29) and autoradiography (30) as described previously (21).

Isolation of RNA and Northern blot analysis. Human skin fibroblasts in $850-\mathrm{cm}^{2}$ roller bottles were incubated with $100 \mathrm{ml}$ of culture medium containing all-trans-retinoic acid $\left(10^{-5}\right.$ and $\left.10^{-6} \mathrm{M}\right)$, dexamethasone $\left(10^{-7} \mathrm{M}\right)$, or the appropriate solvent control. Four roller bottles were employed for each condition, and after 24 or $48 \mathrm{~h}$ of incubation total cytoplasmic RNA was isolated according to established procedures (31). The total RNA was then fractionated on a $1.2 \%$ agarose gel containing 2.2 $\mathrm{M}$ formaldehyde (32), transferred to nitrocellulose filters, and hybridized to a nick-translated collagenase cDNA probe as previously described by Goldberg et al. (33). Hybridization to a nick-translated cDNA TIMP probe was accomplished by incubating the nitrocellulose filter in $10-15 \mathrm{ml}$ of $0.27 \mathrm{M}$ sodium phosphate $(\mathrm{pH}$ 7.2) containing $1 \mathrm{mM}$ EDTA, $1 \% \mathrm{BSA}(\mathrm{wt} / \mathrm{vol})$ and $7 \% \mathrm{SDS}(\mathrm{wt} / \mathrm{vol})$ at $65^{\circ} \mathrm{C}$ for $16 \mathrm{~h}$. The buffer was then replaced with an equal volume of identical buffer containing the ${ }^{32} \mathrm{P}$-labeled cDNA TIMP probe titrated to $10^{-6} \mathrm{cpm} / \mathrm{ml}$, and the filter was exposed to this mixture at $65^{\circ} \mathrm{C}$ for 16-24 h. The filter was then washed twice with $500 \mathrm{ml}$ of buffer at $65^{\circ} \mathrm{C}$ for $15 \mathrm{~min}$. Autoradiography was performed at $-70^{\circ} \mathrm{C}$ using Kodak XAR-5 X-Omat AR film (30).

\section{Results}

The effect of various concentrations of all-trans-retinoic acid on the production of TIMP and collagenase by human skin fibroblasts is shown in Fig. 1. Concentrations of all-trans-retinoic acid ranging from $10^{-8}$ to $10^{-5} \mathrm{M}$ in serum-containing culture medium caused a dose-dependent increase in the secretion of immunoreactive TIMP (Fig. $1 A$ ), reaching levels generally two- to threefold in excess of basal production rates. Production of inhibitor was $50 \%$ of maximal at $\sim 5 \times 10^{-7} \mathrm{M}$ retinoid and maximal at $1 \times 10^{-5} \mathrm{M}$. However, when collagenase production was examined, a biphasic response was observed. Collagenase secretion was sharply diminished in the
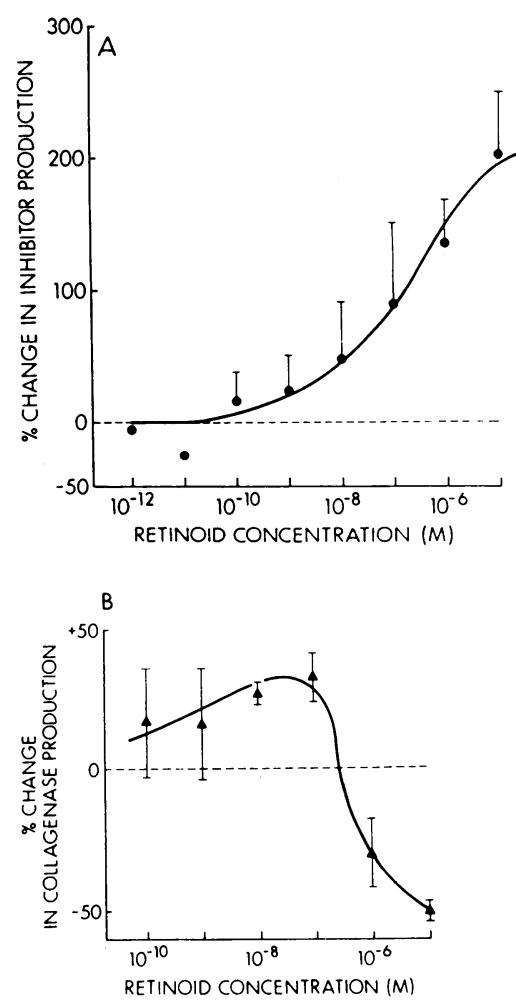

presence of $10^{-5}$ and $10^{-6} \mathrm{M}$ all-trans-retinoic acid, whereas lower retinoid concentrations $\left(10^{-7}-10^{-9} \mathrm{M}\right)$ mildly stimulated the release of this proteinase (Fig. $1 B$ ). The decrease in collagenase secretion, to values less than half of basal production rates, was maximal at $1 \times 10^{-5} \mathrm{M}$ retinoid and $50 \%$ of maximal at $\sim 8 \times 10^{-7} \mathrm{M}$, similar to the corresponding concentrations that modulated TIMP expression. When these experiments were performed in culture medium lacking fetal bovine serum, similar results were obtained (data not shown).

To determine whether this response to retinoic acid was a generalized biologic phenomenon, several lines of human fibroblasts derived from a variety of tissues were next examined. All strains tested, including four lines of adult human skin fibroblasts, two lines of fetal human skin fibroblasts, and one line each of adult lung, fetal lung, and gingival fibroblasts, manifested a significant decrease in collagenase production and a concomitant increase in TIMP secretion when exposed to $10^{-5}$ or $10^{-6} \mathrm{M}$ all-trans-retinoic acid (Table I). The magnitude of the reduction in collagenase secretion produced by the retinoid ranged from $49-74 \%$ of baseline values. The increase in TIMP production ranged from 29 to $230 \%$ of basal rates, averaging $83 \%$. In a single experiment, one line of adult human skin fibroblasts manifested a $618 \%$ increase in inhibitor secretion (CRL 1454; data not shown).

To examine the specificity of the regulatory effects of retinoic acid on TIMP and collagenase production, total new protein synthesis was determined by pulsing culture medium with $\left[{ }^{3} \mathrm{H}\right]$ leucine and measuring isotope incorporation into trichloroacetic acid-insoluble protein. Control cultures incubated for $42 \mathrm{~h}$ before pulse labeling secreted $4.85 \mu \mathrm{g}$ of TIMP/10 $\mu \mathrm{g}$ DNA; in the presence of $10^{-5}$ and $10^{-6} \mathrm{M}$ all-trans-retinoic acid, such cells produced $14.79 \mu \mathrm{g}$ of TIMP/10 $\mu \mathrm{g}$ DNA and $11.65 \mu \mathrm{g}$ of TIMP/10 $\mu \mathrm{g}$ DNA, respectively. After an 8 -h pulse of the same cultures with $\left[{ }^{3} \mathrm{H}\right]$ leucine, the counts per minute precipitated by $20 \%$ trichloroacetic acid in the $10^{-5}$ and $10^{-6}$ $\mathrm{M}$ all-trans-retinoic acid and control cellular lysates were $28,790,38,937$, and 37,843 , respectively. The counts per minute precipitated in the $10^{-5}$ and $10^{-6} \mathrm{M}$ all-trans-retinoic acid and control conditioned media samples were 5,664, 5,703, and 4,869 , respectively. Thus, total protein synthesis was not substantially altered in either cellular lysates or conditioned media by the presence of all-trans-retinoic acid. Total DNA content, determined in this and all other experiments, was also unaffected by retinoic acid conditioning (data not shown).

The time course that characterizes the regulatory action of all-trans-retinoic acid on TIMP and collagenase production was next examined. As shown in Fig. $2 \mathrm{~A}$, during the $1 \mathrm{st} 4 \mathrm{~h}$ of exposure to retinoic acid, there was no apparent effect on the accumulation of TIMP in culture medium. However, after $8 \mathrm{~h}$ of exposure, the retinoic acid-conditioned media contained increased amounts of TIMP as compared with control samples. Maximal stimulation of TIMP synthesis was observed between 24 and $36 \mathrm{~h}$; from 36 to $48 \mathrm{~h}$, the ratio of inhibitor secreted by retinoic acid-conditioned cells vs. untreated cells remained constant. Similar results were obtained for collagenase production (Fig. $2 \mathrm{~B}$ ). An inhibitory effect of all-trans-retinoic acid on collagenase secretion was apparent after $12 \mathrm{~h}$ in culture, and became maximal by $24 \mathrm{~h}$.

Experiments were next performed to examine the release of human skin fibroblasts from the action of all-trans-retinoic acid. Cells were incubated in the presence of $10^{-5} \mathrm{M}$ all-transretinoic acid for $24 \mathrm{~h}$, after which the culture medium was 
Table I. Effect of All-Trans-Retinoic Acid on the Expression of Collagenase and Collagenase Inhibitor by Fibroblasts of Different Tissue Origin

\begin{tabular}{|c|c|c|c|c|c|c|c|c|}
\hline \multirow[b]{3}{*}{ Cell line } & \multicolumn{4}{|c|}{ Collagenase $(\mu \mathrm{g} / 10 \mu \mathrm{g} D N A)$} & \multicolumn{4}{|c|}{ Collagenase inhibitor ( $\mu \mathrm{g} / 10 \mu \mathrm{g}$ DNA) } \\
\hline & \multirow[b]{2}{*}{ Control } & \multicolumn{2}{|c|}{$\begin{array}{l}\text { All-trans-retinoic } \\
\text { Acid }\end{array}$} & \multirow[b]{2}{*}{$\begin{array}{l}\text { Maximal } \\
\text { percent change }\end{array}$} & \multirow[b]{2}{*}{ Control } & \multicolumn{2}{|c|}{ All-trans-retinoic Acid } & \multirow[b]{2}{*}{$\begin{array}{l}\text { Maximal } \\
\text { percent change }\end{array}$} \\
\hline & & $10^{-5}$ & $10^{-6}$ & & & $10^{-5}$ & $10^{-6}$ & \\
\hline & & $M$ & $M$ & $\%$ & & $M$ & $M$ & $\%$ \\
\hline \multicolumn{9}{|c|}{ Human adult skin fibroblasts } \\
\hline CRL 1454 & 7.11 & 3.31 & 4.68 & -53 & 3.61 & 11.91 & 8.66 & +230 \\
\hline CRL 1471 & 3.93 & 1.70 & 3.03 & -57 & 3.93 & 5.34 & 4.77 & +36 \\
\hline GM 4390 & 0.95 & 0.47 & 1.10 & -51 & 3.73 & 7.41 & 5.48 & +99 \\
\hline GM 3651 & 0 & 0 & 0 & - & 2.03 & 3.07 & 4.74 & +133 \\
\hline \multicolumn{9}{|c|}{ Human fetal skin fibroblasts } \\
\hline AG 4449 & 0.46 & 0.24 & n.d. & -49 & 2.39 & 3.03 & 3.09 & +29 \\
\hline EGA 5209 & - & - & - & - & 1.57 & 2.04 & 2.20 & +40 \\
\hline \multicolumn{9}{|c|}{$\begin{array}{l}\text { Human adult lung } \\
\text { fibroblasts }\end{array}$} \\
\hline $\mathrm{BaHa}$ & 0.25 & 0.16 & 0.11 & -57 & 11.78 & 15.99 & 11.89 & +36 \\
\hline \multicolumn{9}{|c|}{ Human fetal lung fibroblasts } \\
\hline Ag 4393 & n.d. & n.d. & n.d. & - & 5.60 & 8.60 & 8.48 & +54 \\
\hline \multicolumn{9}{|c|}{ Human gingival fibroblasts } \\
\hline CRL 1292 & 3.87 & 1.25 & 1.01 & -74 & 20.38 & 38.59 & 32.85 & +89 \\
\hline
\end{tabular}

Confluent monolayer cultures of human fibroblasts derived from various tissues were incubated in serum-containing medium with $10^{-5}$ or $10^{-6}$ $\mathrm{M}$ all-trans-retinoic acid or the appropriate solvent control. At $48 \mathrm{~h}$, the conditioned media were collected for determination of immunoreactive collagenase and TIMP levels by ELISA, and the cells were harvested for measurement of total DNA. Data are expressed as the mean of three or four replicate cultures. The percent change is expressed as the maximal percent increase or decrease in the $10^{-5}$ and $10^{-6}$ conditions, relative to the control value. n.d., Nondetectable.
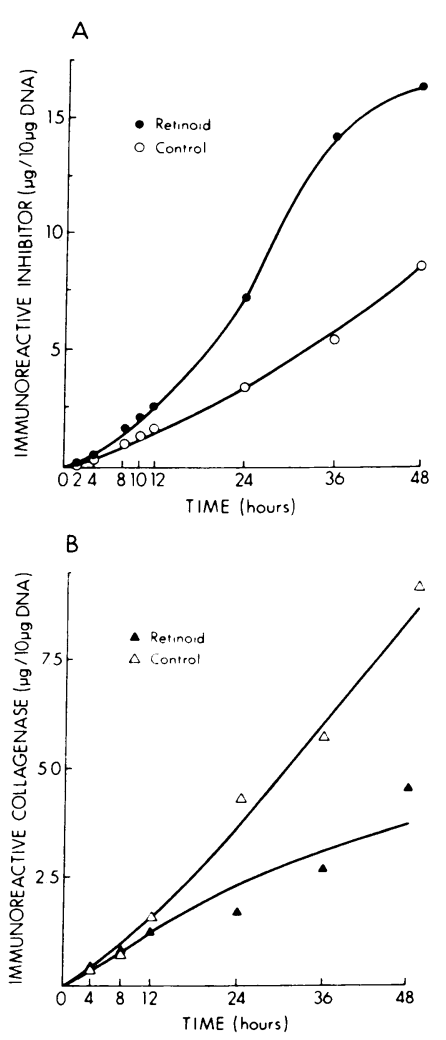

Figure 2. Time course of TIMP $(A)$ and collagenase $(B)$ production after exposure to all-trans-retinoic acid. Confluent cultures of human skin fibroblasts were incubated in culture medium containing $10^{-5} \mathrm{M}$ all-trans-retinoic acid or the appropriate solvent control. Aliquots were removed at $2,4,8,10,12,24,36$, and 48 $\mathrm{h}$ and analyzed for immunoreactive $\operatorname{TIMP}(A)$, and at 4,8 , $12,24,36$, and $48 \mathrm{~h}$ and assayed for immunoreactive collagenase $(B)$ replaced with fresh, otherwise identical medium lacking retinoid and aliquots removed at regular intervals thereafter. As shown in Fig. $3 \mathrm{~A}$, fibroblasts ceased to produce elevated levels of TIMP $\sim 24 \mathrm{~h}$ after the removal of retinoid from culture medium. Similarly, when conditioned media samples were assayed immunologically for collagenase (Fig. $3 \mathrm{~B}$ ), at 4 and $8 \mathrm{~h}$ after the removal of retinoid, enzyme production continued at a diminished level as compared with control cells. However, by $24 \mathrm{~h}$ after removal, the cells preconditioned with retinoic acid were secreting collagenase at the same rate as the untreated cells. Thus, the effects of all-trans-retinoic acid on the production of TIMP and collagenase were essentially indistinguishable with respect to parameters of time of onset, time of maximal effect, and duration of action.

To examine the spectrum of vitamin A derivatives that were capable of stimulating TIMP production, replicate cultures of human skin fibroblasts were exposed to $10^{-5}$ and $10^{-6}$ $\mathrm{M}$ concentrations of all-trans-retinoic acid, 13-cis-retinoic acid, etretinate, etretin, retinal, or retinol (Table II). Conditioned media were collected after $48 \mathrm{~h}$ and assayed for immunoreactive TIMP by ELISA. The naturally occurring retinoic acids, all-trans and 13-cis, showed the greatest capacity to stimulate TIMP production, while incubation with retinal and retinol resulted in more moderate effects. The synthetic retinoid etretinate and its metabolite, etretin, failed to produce a consistent change in the level of immunoreactive TIMP secreted into culture medium. 

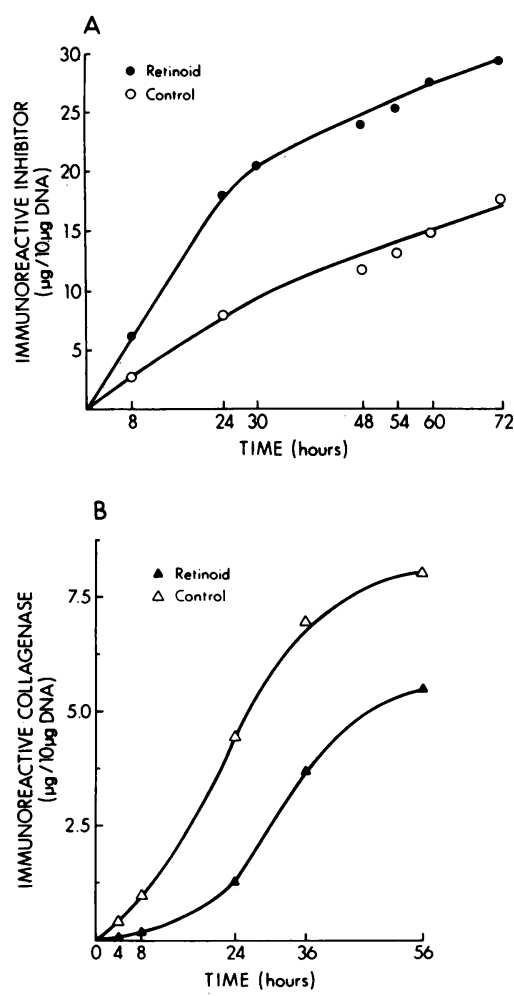

Figure 3. Release of TIMP $(A)$ and collagenase $(B)$ production from the effect of alltrans-retinoic acid. Confluent cultures of human skin fibroblasts were incubated with $10^{-5} \mathrm{M}$ all-trans-retinoic acid or the appropriate concentration of solvent for $48 \mathrm{~h}$, after which the cells were washed and replaced with fresh culture medium lacking retinoid. To determine the recovery of TIMP production $(A)$, aliquots were removed at $8,24,30,48$, 54,60 , and $72 \mathrm{~h}$, as detailed in Methods, and analyzed for immunoreactive inhibitor by ELISA. To determine the recovery of collagenase production $(B)$, aliquots were obtained at $4,8,24,36$, and $56 \mathrm{~h}$ after removal of all-trans-retinoic acid and analyzed for immunoreactive collagenase.

Table II. Effect of Different Retinoid Compounds on the Expression of TIMP by Human Skin Fibroblasts

\begin{tabular}{lllr}
\hline Retinoid & Concentration & $\begin{array}{l}\text { TIMP } \\
(\mu g / 10 \mu g \text { DNA })\end{array}$ & $\begin{array}{r}\text { Percent } \\
\text { change }\end{array}$ \\
\hline Control & $M$ & & $\%$ \\
All-trans-retinoic acid & $10^{-5}$ & $2.58 \pm 0.15$ & \\
& $10^{-6}$ & $4.89 \pm 0.08$ & +90 \\
13-cis-Retinoic acid & $10^{-5}$ & $5.89 \pm 1.05$ & +128 \\
& $10^{-6}$ & $5.22 \pm 0.73$ & +102 \\
Retinal & $10^{-5}$ & $3.58 \pm 0.72$ & +39 \\
& $10^{-6}$ & $4.02 \pm 0.56$ & +56 \\
Retinol & $10^{-5}$ & $4.86 \pm 0.65$ & +89 \\
& $10^{-6}$ & $4.56 \pm 0.30$ & +77 \\
Etretinate & $10^{-5}$ & $4.26 \pm 0.40$ & +65 \\
& $10^{-6}$ & $3.10 \pm 0.22$ & +20 \\
Etretin & $10^{-5}$ & $2.50 \pm 0.40$ & -3 \\
& $10^{-6}$ & $3.84 \pm 0.25$ & +49 \\
& & $3.36 \pm 0.42$ & +30
\end{tabular}

Human skin fibroblasts were incubated with $10^{-5}$ or $10^{-6} \mathrm{M}$ concentrations of different retinoid compounds for $48 \mathrm{~h}$, as detailed in Methods. Aliquots of conditioned media were tested for immunoreactive inhibitor by ELISA, and the cell layer was analyzed for DNA content. The data are expressed as the mean values of four different experiments, plus or minus the standard error, each using a different cell line of human skin fibroblasts. Percent change indicates the increase in TIMP production as compared with the appropriate $\mathrm{Me}_{2} \mathrm{SO}$ control.
To gain insight into the mechanisms whereby retinoic acid alters the pattern of TIMP and collagenase production by human fibroblasts, metabolic labeling and immunoprecipitation studies as well as Northern hybridization analyses were performed. Human skin fibroblasts, either untreated or retinoid-conditioned, were exposed to $\left[{ }^{3} \mathrm{H}\right]$ leucine, and the labeled medium proteins were subjected to immunoprecipitation using TIMP-specific antibody $(2,5)$. As shown in Fig. 4, the fibroblasts exposed to $10^{-5}$ or $10^{-6} \mathrm{M}$ retinoic acid synthesized greater quantities of TIMP than untreated cells. Furthermore, this increase in the biosynthesis of TIMP paralleled the increased amounts of inhibitor protein secreted into culture medium as measured by ELISA. Assessment of TIMP and collagenase mRNA levels in response to retinoid treatment was accomplished by the isclation of total RNA and Northern blot analysis. As shown in Fig. 5, fibroblasts incubated with $10^{-5}$ and $10^{-6} \mathrm{M}$ all-trans-retinoic acid possessed much higher steady state levels of TIMP mRNA than control cells. Fibroblasts incubated with $10^{-5} \mathrm{M}$ all-trans-retinoic acid contained significantly lower steady state levels of collagenase mRNA than control cells. Furthermore, such changes in steady state mRNA levels paralleled the changes observed in immunoreactive TIMP and collagenase present in the culture medium conditioned by these cells. Thus, the stimulation in TIMP production by retinoic acid appears to be mediated via an increase in the biosynthesis of new inhibitor protein and is accompanied by a parallel increase in steady state levels of inhibitor mRNA. Similarly, the diminution in collagenase production caused by retinoic acid is mirrored by reduced steady state levels of collagenase mRNA.

We now focused our attention on whether the glucocorticoid compounds, agents known to suppress collagenase production $(12,24,25)$, can also regulate TIMP expression. Human skin fibroblasts in monolayer culture were incubated with concentrations of dexamethasone ranging from $10^{-11}$ to $10^{-7} \mathrm{M}$ under serum-free conditions for $48 \mathrm{~h}$. Conditioned media were then collected and assayed for both collagenase and TIMP by ELISA. As shown in Fig. 6, dexamethasone induced a dose-dependent decrease in immunoreactive collagenase, but failed to alter appreciably the amounts of secreted TIMP. Such results were also observed using three additional human skin fibroblast cell lines, subjected to either dexamethasone or hydrocortisone (data not shown). Experiments per-

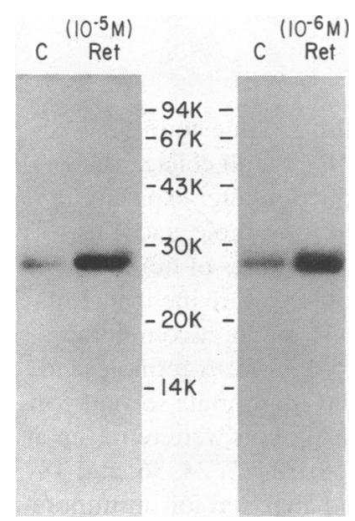

Figure 4. Metabolic labeling and immunoprecipitation of TIMP. Confluent cultures of human skin fibroblasts were conditioned for $24 \mathrm{~h}$ with $10^{-5}$ or $10^{-6} \mathrm{M}$ all-trans-retinoic acid or $\mathrm{Me}_{2} \mathrm{SO}$. The cells were then exposed to $\left[{ }^{3} \mathrm{H}\right]$ leucine for $24 \mathrm{~h}$ as detailed in Methods, and the labeled medium proteins were subjected to immunoprecipitation using TIMPspecific antibody. ELISA measurements were simultaneously performed on the labeled conditioned media, providing values for immunoreactive TIMP of $5.67 \mu \mathrm{g} / 10 \mu \mathrm{g}$ DNA with $10^{-5} \mathrm{M}$ retinoic acid exposure vs. $1.66 \mu \mathrm{g} / 10 \mu \mathrm{g}$ DNA for the control sample. Fibroblasts conditioned with $10^{-6} \mathrm{M}$ retinoic acid produced $6.33 \mu \mathrm{g} / 10 \mu \mathrm{g}$ DNA vs. $1.75 \mu \mathrm{g} / 10 \mu \mathrm{g}$ DNA for the control. C, control; Ret, retinoic acid. 

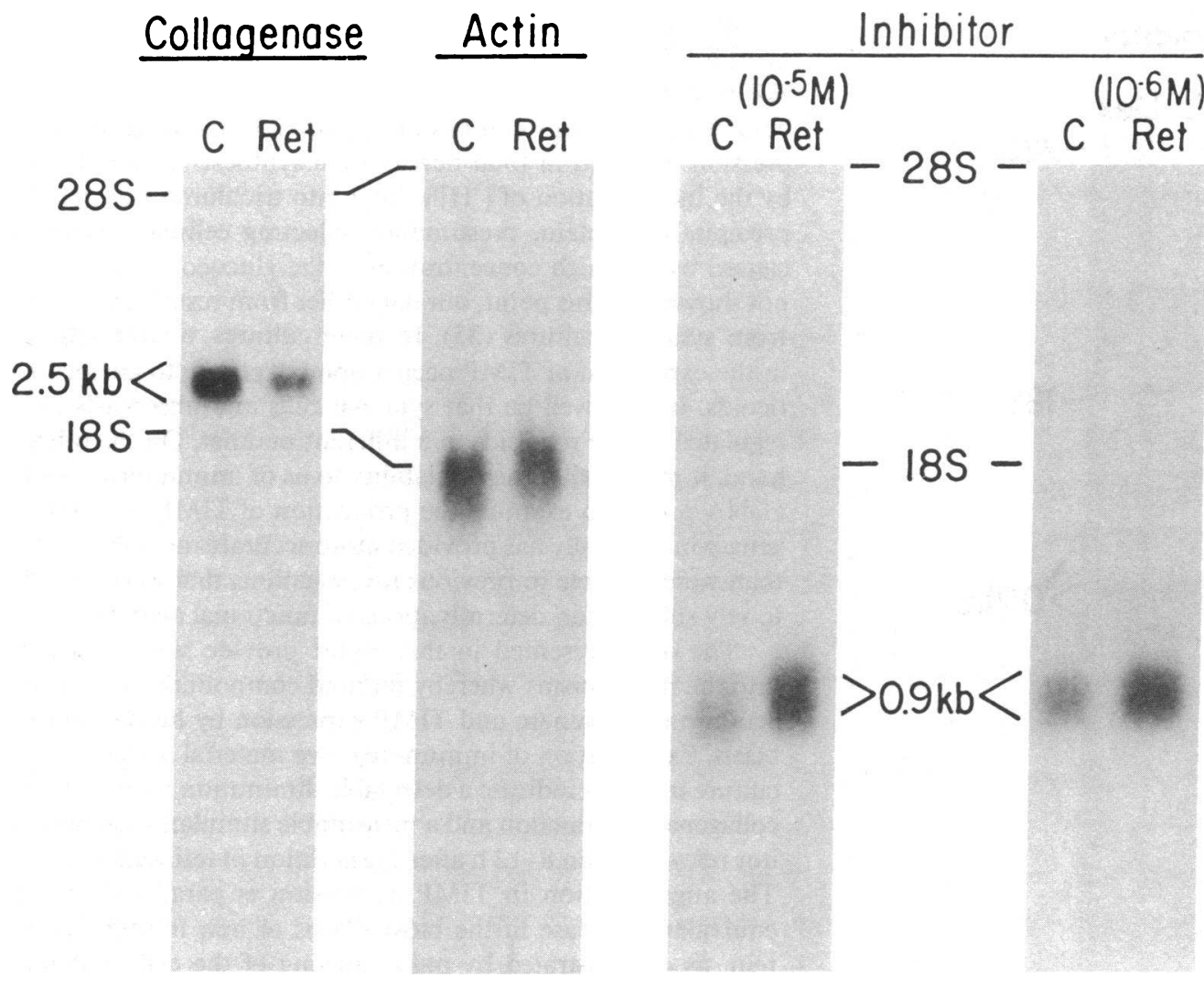

Figure 5. Steady state mRNA levels after treatment with retinoic acid. Confluent human skin fibroblasts were incubated for $48 \mathrm{~h}$ with $10^{-5}$ or $10^{-6} \mathrm{M}$ all-trans-retinoic acid or $\mathrm{Me}_{2} \mathrm{SO}$, as detailed in Methods. The cell layer was employed for RNA isolation while the conditioned media were subjected to ELISA. Total cytoplasmic RNA was harvested, and Northern hybridizations performed using TIMP and collagenase cDNA probes. The same samples of total RNA (control vs. retinoic acid) were utilized in each Northern blot at $10^{-5} \mathrm{M}$ retinoic acid (TIMP, actin, and collagenase). $10 \mu \mathrm{g}$ of total RNA were applied per slot. The TIMP cDNA hybridized to mRNA of 0.9 kilobase $(\mathrm{kb})$ in size (8), whereas the collagenase cDNA hybridized to mRNA of $2.5 \mathrm{~kb}$ (33). ELISA measurements of the retinoic acid vs. control media showed $9.68 \mu \mathrm{g}$ TIMP $/ 10^{6}$ cells vs. $3.99 \mu \mathrm{g}$ TIMP $/ 10^{6}$ cells, and $0.12 \mu \mathrm{g}$ collagenase $/ 10^{6}$ cells vs. $0.29 \mu \mathrm{g}$ collagenase $/ 10^{6}$ cells, respectively, for cells conditioned with $10^{-5} \mathrm{M}$ all-trans-retinoic acid. When $10^{-6} \mathrm{M}$ retinoic acid was employed, values of $7.42 \mu \mathrm{g}$ TIMP $/ 10^{6}$ cells vs. $4.25 \mu \mathrm{g}$ TIMP $/ 10^{6}$ cells (control) were obtained. C, control; Ret, retinoic acid.

formed in the presence of serum gave less consistent collagenase effects and required higher concentrations of the glucocorticoids, presumably due to steroid binding to serum proteins (data not shown).

To analyze these glucocorticoid effects further, total RNA was harvested from dexamethasone-treated and control fibroblasts and subjected to Northern hybridization using TIMP and collagenase cDNA probes. As shown in Fig. 7, fibroblasts incubated in the presence of $10^{-7} \mathrm{M}$ dexamethasone contained much reduced steady state levels of collagenase mRNA as compared with control cells, but very similar amounts of TIMP mRNA. Thus, both the protein and mRNA data suggest that glucocorticoids are potent suppressors of collagenase pro-

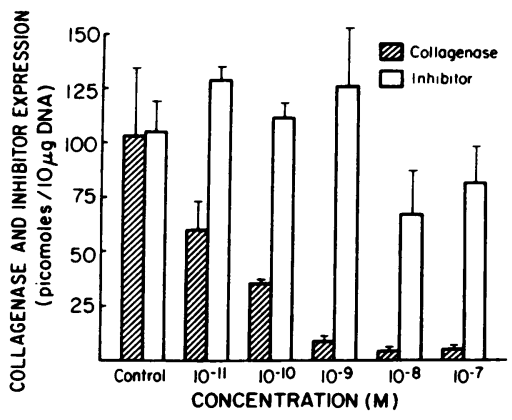

Figure 6. Effect of dexamethasone on the production of TIMP and collagenase. Confluent cultures of human skin fibroblasts were incubated with the indicated concentrations of dexamethasone or solvent control for $48 \mathrm{~h}$, as detailed in Methods. Aliquots of conditioned media were assayed for

immunoreactive TIMP and collagenase. The data are expressed as the level of each immunoreactive protein in culture media in picomoles per $10 \mu \mathrm{g}$ DNA $( \pm \mathrm{SD})$. duction, but do not modulate TIMP expression to any significant extent.

\section{Discussion}

The data presented in this report clearly indicate that the regulation of fibroblast interstitial collagenase and TIMP, proteins integrally involved in collagen turnover, can occur by a variety of mechanisms. The retinoid compounds, a group of naturally occurring and synthetic vitamin A derivatives, appear to induce a specific increase in the biosynthesis of TIMP, while concomitantly causing a selective reduction in collagenase production. Our results, therefore, both confirm and extend the earlier preliminary observations of Bauer et al. (23) and Brinckerhoff et al. (34). These effects, by and large, are present only at higher retinoid concentrations $\left(10^{-5}\right.$ and $\left.10^{-6} \mathrm{M}\right)$, but are apparent in human fibroblasts of diverse tissue origin, including skin, lung, and gingiva, whether the cells are adult or fetal in nature. Modulation of collagenase and TIMP expression by retinoids is therefore very different from the regulatory effects exerted upon these proteins that have been previously described for phorbol esters $(20,21)$ and the cytokine IL-1 (20). Both the phorbol compounds and IL-1 cause selective augmentation in the production of collagenase and TIMP, leading to consideration of the possibility that their release from cells is usually modulated in same direction, perhaps even in a coordinate manner. Our findings demonstrate that this need not be the case and that the synthesis and release of interstitial collagenase and TIMP may be governed by a vari- 


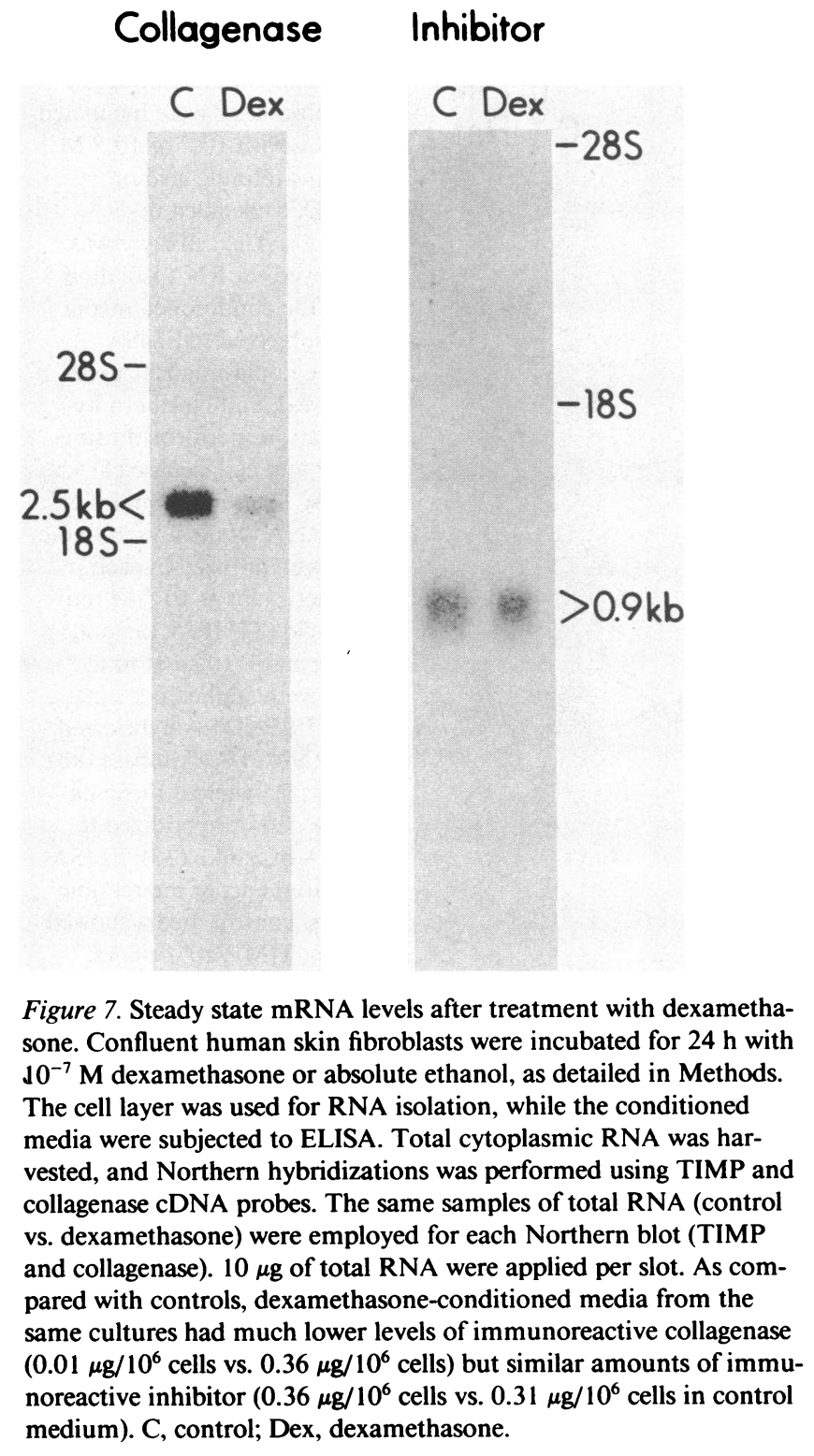

ety of mechanisms. Expression appears to be co-regulated in an inverse manner by retinoids and independently modulated by dexamethasone, but elucidation of the exact intracellular mechanisms underlying the effects of such agents will require additional studies directed at the gene level.

The ability of glucocorticoid compounds such as hydrocortisone and dexamethasone to suppress interstitial collagenase production has been well established by a variety of previous investigations $(12,24,25)$. This phenomenon has been a consistent finding in studies of human fibroblasts (25), human skin explants (12), and rat uterus explants (12). In the present report, we have also documented the capacity of dexamethasone to induce a marked diminution in collagenase production from human skin fibroblasts, as evidenced by both decreased secretion of immunoreactive material into culture medium and by suppressed steady state levels of enzyme-specific mRNA (Figs. 6 and 7). However, even at concentrations of dexamethasone as high as $10^{-7} \mathrm{M}$, sufficient to suppress collagenase production by $\sim 70 \%$, there was no effect observed on either immunoreactive TIMP protein secreted into culture medium or in steady state levels of TIMP mRNA by Northern hybridization. Higher concentrations of dexamethasone $\left(10^{-6}\right.$ $M$ ) in serum-free medium reduced the production of TIMP, but always by an amount essentially equal to the level of suppression observed in total new protein synthesis as measured by the incorporation of $\left[{ }^{3} \mathrm{H}\right]$ leucine into trichloroacetic acidprecipitable protein, presumably reflecting cellular toxicity caused by this high concentration of the glucocorticoid (data not shown). At this point, our data differ from results obtained from synovial cultures (35). In these cultures, a stimulation in the expression of TIMP occurs upon exposure to glucocorticoids. It may well be that synovial cells and fibroblasts are regulated by the retinoids in a different manner. On the other hand, it may be that the availability to us of immunologic and cDNA probes to examine the production of TIMP and collagenase individually has provided more accurate measurements than were possible in previous investigations that were forced to rely solely upon determinations of functional activity.

The data presented in this report provide some insights into the mechanisms whereby retinoid compounds exert their action on collagenase and TIMP expression by human fibroblasts. Examination of immunoreactive material secreted into culture medium indicate a detectable diminution in the rate of collagenase production and a measurable stimulation of inhibitor release within 8-12 $\mathrm{h}$ after the addition of retinoid (Fig. 2). The augmentation in TIMP expression is paralleled by an equivalent increase in the biosynthesis of new inhibitor protein, as demonstrated by pulse labeling of the cells and immunoprecipitation usign TIMP-specific antibody (Fig. 4). Furthermore, these events are also correlated with the presence of elevated steady state levels of TIMP mRNA as measured in Northern blot analysis using a specific cDNA probe (Fig. 5). Previous work has demonstrated that all-trans-retinoic acid diminishes collagenase production via a transcriptional mechanism, decreasing collagenase mRNA steady state levels without affecting mRNA half-life (36). Our findings confirm this work in part, in that the decrease in collagenase released from retinoic acid-exposed cells was mirrored by substantially reduced levels of collagenase mRNA isolated from such fibroblasts, and also suggest that the vitamin A derivatives exert their effects upon TIMP expression at a transcriptional level of regulation. In any event, the results presented in Fig. 3 also clearly indicate that the effect of retinoid compounds upon such cells is reversible. Within $\sim 24 \mathrm{~h}$ after the removal of retinoic acid from culture medium, basal levels of both collagenase and TIMP secretion from the cells are resumed.

The results of our experiments may also have implications regarding the in vivo effects of retinoid and glucocorticoid compounds on collagen metabolism and connective tissue turnover. In the case of the glucocorticoids, there is considerable evidence that such compounds markedly diminish collagen synthesis (37), also decrease collagenase production (12, $24,25)$, and from the present data appear to have no effect on the elaboration of TIMP. Although this modulation of collagen and collagenase expression would be expected to result in opposing influences upon collagen turnover, the effect of glucocorticoids on the structural protein's biosynthesis is likely to be the dominant factor, as such agents clearly reduce the mass of connective tissues when employed pharmacologically (38). Similarly, the vitamin A derivatives have been reported to decrease collagen synthesis in vitro (39), and also decrease the production of interstitial collagenase $(14,22,36)$. From the 
experiments detailed in the present report, however, this reduction in collagenase expression is accompanied by a concomitant stimulation in the elaboration of TIMP. These findings may have implications for pathological states of connective tissue turnover in which maintaining a mature connective tissue matrix, rather than enhancing the deposition of collagen, is a therapeutic goal. The fact that the effect on collagenase and TIMP expression could be demonstrated in a variety of human fibroblasts from different tissues of origin suggests that systemic retinoid administration could result in widespread effects on connective tissue turnover. Furthermore, it would appear that retinoid compounds that are capable of enhancing TIMP biosynthesis (Table II) are the same ones that suppress collagenase release (23). Our studies indicate that the naturally occurring retinoic acids, all-trans-retinoic and 13cis-retinoic acids, are quite potent in stimulating TIMP production, whereas the synthetic compounds etretinate and its metabolite etretin have little or no significant effect. However, these effects are produced only at the higher levels of retinoids employed in this study, concentrations of at least $10^{-6} \mathrm{M}$. In fact, our data provide evidence that collagenase modulation may be biphasic in nature, with some stimulation of enzyme production occurring at lower retinoid concentrations (Fig. 1).

Whereas the regulation of collagen turnover is undoubtedly a complex biologic process involving not only the production of collagenase and TIMP, but also factors such as procollagenase activation, extracellular compartmentalization, and the formation and removal of enzyme-inhibitor complexes, our data do suggest that there are a variety of mechanisms whereby regulatory agents can modulate the expression of these fibroblast proteins. Further complexity is added by the knowledge that proteins identical to fibroblast interstitial collagenase and TIMP are elaborated by other cell types such as mononuclear phagocytes (5), which likely participate in mediating collagen turnover both in normal connective tissue metabolism and in disease states. Future investigations will therefore necessarily focus upon aspects of the regulation and interplay of such resident and inflammatory cells in modulating collagen turnover.

\section{Acknowledgments}

We thank Catherine Fliszar, Nadean Brown, and Michael Lagunoff for their excellent technical assistance. The authors are grateful to Drs. G. Goldberg and A. Eisen, Washington University School of Medicine, for use of a collagenase cDNA probe (33). We also thank Drs. E. Bauer and $J$. Jeffrey for helpful discussions during the preparation of this manuscript.

This work was supported by United States Public Health Service grants AM 35805 and TO-AM 07284. Dr. Welgus is the recipient of Research Career Development Award AM 01525.

\section{References}

1. Gross, J., and Y. Nagai. 1965. Specific degradation of the collagen molecule by tadpole collagenolytic enzyme. Proc. Natl. Acad. Sci. USA. 54:1197-1204.

2. Stricklin, G. P., and H. G. Welgus. 1983. Human skin fibroblast collagenase inhibitor: purification and biochemical characterization. $J$. Biol. Chem. 258:12252-12258.

3. Welgus, H. G., and G. P. Stricklin. 1983. Human skin fibroblast collagenase inhibitor: comparative studies in human connective tissues, serum, and amniotic fluid. J. Biol. Chem. 258:12259-12264.

4. Sellers, A., G. Murphy, M. C. Meikle, and J. J. Reynolds. 1979.
Rabbit bone collagenase inhibitor blocks the activity of other neutral metalloproteinases. Biochem. Biophys. Res. Commun. 87:581-587.

5. Welgus, H. G., E. J. Campbell, Z. Bar-Shavit, R. M. Senior, and S. L. Teitelbaum. 1985. Human alveolar macrophages produce a fibroblast-like collagenase and collagenase inhibitor. J. Clin. Invest. 76:219-224.

6. Cooper, T. E., A. Z. Eisen, G. P. Stricklin, and H. G. Welgus. 1985. Platelet-derived collagenase inhibitor: characterization and subcellular localization. Proc. Natl. Acad. Sci. USA. 82:2779-2783.

7. Docherty, A. J. P., A. Lyons, B. J. Smith, E. M. Wright, P. E. Stephens, T. J. R. Harris, G. Murphy, and J. J. Reynolds. 1985. Sequence of human tissue inhibitor of metalloproteinases and its identity to erythroid-potentiating activity. Nature (Lond.). 318:66-69.

8. Carmichael, D. F., A. Sommer, R. C. Thompson, D. C. Anderson, C. G. Smith, H. G. Welgus, and G. P. Stricklin. 1986. Primary structure and cDNA cloning of human fibroblast collagenase inhibitor. Proc. Natl. Acad. Sci. USA. 83:2407-2411.

9. Welgus, H. G., G. P. Stricklin, A. Z. Eisen, E. A. Bauer, R. V. Cooney, and J. J. Jeffrey. 1979. A specific inhibitor of vertebrate collagenase produced by human skin fibroblasts. J. Biol. Chem. 254:1938-1943.

10. Cawston, T. E., G. Murphy, E. Mercer, W. A. Galloway, B. L. Hazelman, and J. J. Reynolds. 1983. The interaction of purified rabbit bone collagenase with purified rabbit bone metalloproteinase inhibitor. Biochem. J. 211:313-318.

11. Welgus, H. G., J. J. Jeffrey, A. Z. Eisen, W. T. Roswit, and G. P. Stricklin. 1985. Human skin fibroblast collagenase: interaction with collagen and collagenase inhibitor. Collagen Relat. Res. 5:167-179.

12. Koob, T. J., J. J. Jeffrey, and A. Z. Eisen. 1974. Regulation of human skin collagenase activity by hydrocortisone and dexamethasone in organ culture. Biochem. Biophys. Res. Commun. 61:10831088.

13. Dayer, J.-M., J. Breard, L. Chess, and S. M. Krane. 1979. Participation of monocyte-macrophages and lymphocytes in the production of a factor that stimulates collagenase and prostaglandin release by rheumatoid synovium. J. Clin. Invest. 64:1386-1392.

14. Brinckerhoff, C. E., R. M. McMillan, J.-M. Dayer, and E. D. Harris, Jr. 1980. Inhibition by retinoic acid of collagenase production in rheumatoid synovial cells. N. Engl. J. Med. 303:432-436.

15. Bauer, E. A., T. W. Cooper, D. R. Tucker, and N. B. Esterly. 1980. Phenytoin therapy of recessive dystrophic epidermolysis bullosa: clinical trial and proposed mechanism of action on collagenase. $N$. Engl. J. Med. 303:776-781.

16. Mizel, T. P., J.-M. Dayer, S. M. Krane, and S. E. Mergenhagen. 1981. Stimulation of rheumatoid synovial cell collagenase and prostaglandin production by partially purified lymphocyte-activating factor (Interleukin 1). Proc. Natl. Acad. Sci. USA. 78:2474-2477.

17. Brinckerhoff, C. E., N. H. Gross, H. Nagase, L. Sheldon, R. C. Jackson, and E. D. Harris, Jr. 1982. Increased level of translatable collagenase messenger ribonucleic acid in rabbit synovial fibroblasts treated with phorbol myristate acetate or crystals of monosodium urate monohydrate. Biochemistry. 21:2674-2679.

18. Postlethwaite, A. E., L. B. Lachman, C. L. Mainardi, and A. H. Kang. 1983. Interleukin 1 stimulation of collagenase production by cultured fibroblasts. J. Exp. Med. 157:801-806.

19. Bauer, E. A., T. W. Cooper, J. S. Huang, J. Altman, and T. F. Deuel. 1985. Stimulation of in vitro human skin collagenase expression by platelet-derived growth factor. Proc. Natl. Acad. Sci. USA. 82:4132-4136.

20. Murphy, G., J. J. Reynolds, and Z. Werb. 1985. Biosynthesis of tissue inhibitor of metalloproteinases by human fibroblasts in culture: stimulation by 12-O-tetradecanoylphorobol 13-acetate and interleukin-1 in parallel with collagenase. J. Biol. Chem. 260:3079-3083.

21. Clark, S. D., S. M. Wilhelm, G. P. Stricklin, and H. G. Welgus. 1985. Co-regulation of collagenase and collagenase inhibitor production by phorbol myristate acetate in human skin fibroblasts. Arch. Biochem. Biophys. 241:36-44.

22. Bauer, E. A., J. L. Seltzer, and A. Z. Eisen. 1982. Inhibition of 
collagen degradative enzymes by retinoic acid in vitro. J. Am. Acad. Dermatol. 6:603-607.

23. Bauer, E. A., J. L. Seltzer, and A. Z. Eisen. 1983. Retinoic acid inhibition of collagenase and gelatinase expression in human skin fibroblast cultures: evidence for a dual mechanism. J. Invest. Dermatol. 81:162-169.

24. Koob, T. J., J. J. Jeffrey, A. Z. Eisen, and E. A. Bauer. 1980. Hormonal interactions in mammalian collagenase regulation: comparative studies in human skin and rat uterus. Biochim. Biophys. Acta. 629:13-23.

25. Bauer, E. A., A. Kronberger, K.-J. Valle, J. J. Jeffrey, and A. Z. Eisen. 1985. Glucocorticoid modulation of collagenase expression in human fibroblast cultures: evidence for pre-translational inhibition. Biochim. Biophys. Acta. 825:227-235.

26. Eisen, A. Z., J. J. Jeffrey, and J. Gross. 1968. Human skin collagenase: isolation and mechanism of attack on the collagen molecule. Biochim. Biophys. Acta. 151:637-645.

27. Cooper, T. W., E. A. Bauer, and A. Z. Eisen. 1982. Enzymelinked immunosorbent assay for human skin collagenase. Collagen Relat. Res. 3:205-216.

28. Burton, K. 1968. Determination of DNA concentration with diphenylamine. In Methods and Enzymology. L. Grossman and $\mathrm{K}$. Moldave, editors. Academic Press, New York. Vol. 12:163-166.

29. King, J., and U. K. Laemmli. 1971. Polypeptides of the tail fibers of bacteriophage T4. J. Mol. Biol. 62:465-477.

30. Lasky, R. A., and A. D. Mills. 1975. Quantitative film detection of ${ }^{3} \mathrm{H}$ and ${ }^{14} \mathrm{C}$ in polyacrylamide gels by fluorography. Eur. J. Biochem. $56: 335-341$.

31. Chirgwin, J. M., A. E. Przybyla, R. J. MacDonald, and W. J. Rutter. 1979. Isolation of biologically active ribonucleic acid from sources enriched in ribonuclease. Biochemistry. 18:5293-5299.
32. Maniatis, T., E. F. Fritsch, and J. Sambrook. 1982. Electrophoresis of RNA through gels containing formaldehyde. In Molecular Cloning: A Laboratory Manual. Cold Spring Harbor Laboratory, Cold Spring Harbor, New York. 202-203.

33. Goldberg, G. I., S. M. Wilhelm, A. Kronberger, E. A. Bauer, G. A. Grant, and A. Z. Eisen. 1986. Human fibroblast collagenase: complete primary structure and homology to an oncogene transformation-induced rat protein. J. Biol. Chem. 261:6600-6605.

34. Brinckerhoff, C. E., C. A. Vater, and E. D. Harris, Jr. 1981. Effects of retinoids on rabbit synovial fibroblasts and chondrocytes. In Cellular Interactions. J. T. Dingle and J. Gordon, editors. Elsevier/ North-Holland Scientific Publishers, Ltd., Limerick, Ireland. 215-230.

35. McGuire, B., G. Murphy, J. J. Reynolds, and R. G. G. Russell. 1981. Production of collagenase and inhibitor (TIMP) by normal, rheumatoid and osteoarthritic synovium in vitro: effects of hydrocortisone and indomethacin. Clin. Sci. (Lond.). 61:703-710.

36. Brinckerhoff, C. E., I. M. Plucinska, L. A. Sheldon, and G. T. O'Connor. 1986. Half-life of synovial cell collagenase messenger-RNA is modulated by phorbol-myristate acetate but not by all-trans-retinoic acid or dexamethasone. Biochemistry. 25:6378-6384.

37. Baxter, J. D., and J. W. Fundu. 1979. Medical progress: hormone receptors. N. Engl. J. Med. 301:1149-1161.

38. Vickers, C. F. H. 1986. Topical corticosteroids. In Dermatology in General Medicine. T. B. Fitzpatrick, A. Z. Eisen, K. Wolff, I. M. Freedberg, and K. F. Austen, editors. McGraw-Hill, Minneapolis. Vol. 2. 2540-2545.

39. Oikarinen, H., A. I. Oikarinen, E. M. L. Tan, R. P. Abergel, C. A. Mecker, M.-L. Chu, D. J. Prockop, and J. Uitto. 1985. Modulation of procollagen gene expression by retinoids. J. Clin. Invest. 75:1545-1553. 